\title{
Antimicrobial Potential of Ethnomedicinal Ferns of Southern Assam, India
}

\author{
K. NATH* ${ }^{*}$ M. K. BHATTACHARYAAND S. KAR ${ }^{1}$
}

Department of Botany and Biotechnology, ${ }^{1}$ Department of Chemistry, Karimganj College, Karimganj-788 710, India

Nath et al.: Antimicrobial Ethnomedicinal Ferns of South Assam

Since ancient times traditional herbal medicines has been the basis of treatment for many ailments. Extracts of medicinal plants are rich source of unique phytochemicals. In the present study extract of 12 pteridophytes collected from Southern Assam were studied for antibacterial activities. The frond extract of these species was tested against five non-pathogenic and pathogenic bacteria, Bacillus subtilis, Escherichia coli, Pseudomonas aeruginosa, Staphylococcus aureus and Proteus vulgaris. The results obtained indicated that 6 ferns exhibited antibacterial activity against one or more organisms while the remaining 6 ferns did not show any antibacterial activity. The ferns showing antibacterial activity were Christella parasitica, Microlepia speluncae, Pteris multifida, Microsorum pteropus, Adiantum caudatum, Pteris vittata. 


\section{Key words: Ethnomedicine, ferns, antibacterial activity}

Microorganisms have survived for thousands of years by their ability to adapt with the changing environment. They especially do so by responding to various antimicrobial agents such as antibiotics, which is attained either by spontaneous mutation, DNA transfer or by human activities such as irrational use of antibiotic, lack of consciousness regarding the rules and value of good hygiene in hospitals, prolonged medical care and also via use of other agents aimed at destroying bacteria, namely the surface antibacterials now available in many household products. All this enables microbes to oppose the action of certain antibiotics or group of antibiotics, rendering the antibiotics ineffective and resulting in the emergence of multidrug resistant microorganisms ${ }^{[1]}$. These multidrug resistant organisms are now-a-days becoming very hard to treat with the commercially available antibiotics. Since no new antibiotics have been discovered in the last few decades, the emergence of multidrug resistant organisms is often resulting into treatment failure. This continuous appearance of bacterial resistance to different group of antibiotics has increased the demand for more effective antimicrobial agents. It has been found that there are various medicinal or ethnomedicinal plants, which are being used by tribal, ethnic or by rural population for the treatment of a number of ailments such as cuts, burns and skin diseases. The use of the extracts of these medicinal plants alone or in combination with the available antibiotics might help in the treatment of infections by resistant microorganisms leading to treatment success. It is known that more than 400000 species of tropical flowering plants have medicinal uses and this makes the traditional medicines more economical than modern medicine ${ }^{[2]}$. The use of medicinal plants to treat diseases in China, India and South Africa have been reported to contributes significantly to primary health care.

Further, the frequency of life threatening infections caused by pathogenic microorganisms and their rapid spread from one continent to the other in the age of globalization has also encouraged different researchers to probe for newer antimicrobial agents. In recent years, attempts have been made to investigate a variety of indigenous drugs especially of plant origin against infectious diseases ${ }^{[3,4]}$.
Recently some pteridophytes have been identified to possess antimicrobial properties. The antimicrobial activity in the extracts of 114 species of pteridophytes belonging to 61 genera and 27 families was studied and the results revealed that $64 \%$ of the samples examined possessed antimicrobial activity ${ }^{[5]}$. The extract of the fern, Nephrolepis sp. when mixed with $\alpha$-D-oligogalacturonides promoted the production of an antibiotic compounds ${ }^{[6]}$. Cheilanthes viridis, which is one of the most commonly used ferns in the treatment of wounds in Eastern Cape, South Africa possessed very good antimicrobial activity ${ }^{[7]}$. Plant extracts were used successfully by various investigators to study antimicrobial activity. Pteridophytes possessed antimicrobial properties mainly due to the presence of various secondary phytochemicals such as phenols, flavonoids and steroids.

The manifestation of newer infectious diseases, increase in pathogen resistance and renaissance of several infections are the driving force behind various researchers at both national and international level to explore to identify and develop novel antimicrobial agents. Therefore, in the present investigation an effort has been made to investigate the antibacterial activity of some common ferns, collected from different places of Southern Assam.

Fresh plant material was collected from various places of Southern Assam for a period of 6 mo, i.e. March to August, 2014. The collected plants were cleaned under tap water and were allowed to shade dry. The shade dried plants were then ground to a powder. Five grams of each plant powder was macerated in $20 \mathrm{ml}$ each of 4 different solvents, water, methanol, acetone and petroleum ether for $72 \mathrm{~h}$. After $72 \mathrm{~h}$ the extract was filtered through a Whatman filter paper No. 1. The extracts were then allowed to stand at room temperature for the solvent to evaporate. In case of the aqueous extract, the extract was kept in a hot water bath at $50^{\circ}$

This is an open access article distributed under the terms of the Creative Commons Attribution-NonCommercial-ShareAlike 3.0 License, which allows others to remix, tweak, and build upon the work non-commercially, as long as the author is credited and the new creations are licensed under the identical terms

Accepted 09 April 2018

Revised 26 August 2017

Received 06 February 2017

Indian J Pharm Sci 2018;80(3):556-560 
for evaporation. The dried plant extracts were then stored in a refrigerator at $4^{\circ}$.

Test organisms were collected from the culture collection of the Institute of Microbial Technology (IMTECH), Chandigarh. These included Bacillus subtilis (MTCC NO. 736), Escherichia coli (MTCC NO. 1610), Pseudomonas aeruginosa (MTCC NO. 3541), Staphylococcus aureus (MTCC NO. 3160), Proteus vulgaris (MTCC NO. 1771). The bacteria were sub-cultured on nutrient agar (HiMedia M0010100G) plates and incubated at $37^{\circ}$ for $24 \mathrm{~h}$ and stored at $4^{\circ}$ in the refrigerator to maintain stock culture. Organisms were maintained at $-80^{\circ}$ and $-20^{\circ}$ refrigerators in a glycerol stock.

The inoculum for antibacterial assay was prepared by inoculating freshly grown bacterial culture in normal saline solution and the turbidity was matched with 0.5 McFarland standard. Mueller-Hinton agar medium was employed for disc diffusion antibacterial testing. Dehydrated medium supplied by Sisco Research Laboratories (SRL) Pvt. Ltd., Mumbai was used. The medium contained per litre, beef infusion from $300 \mathrm{~g}$ beef, acid hydrolysate of casein $17.5 \mathrm{~g}$, starch $1.5 \mathrm{~g}$ and agar $17 \mathrm{~g}$. The medium was prepared by dissolving the dehydrated mixture of ingredients in distilled water. After boiling, $\mathrm{pH}$ was adjusted to 7.4 and sterilized by autoclaving at $121^{\circ}$ for $15 \mathrm{~min}$. The medium was poured in Petri plates.

The Mueller-Hinton agar plates were seeded with bacterial inoculums aided with sterile swab and was allowed to dry for $30 \mathrm{~min}$. Then on the seeded plates, sterile filter paper discs were placed, which were impregnated with $10 \mu \mathrm{l}$ of each plant extract $(500 \mathrm{mg} / 500 \mu \mathrm{l}$ of solvent). For negative control discs impregnated with each of the solvent was used. The plates were then incubated at $37^{\circ}$ for $24 \mathrm{~h}$.

The emergence of multidrug resistance microorganisms made treatment of infections very difficult with commercially available antibiotics. But there available various medicinal or ethnomedicinal plants, which are being used by tribal, ethnic and rural population for the treatment of a number of diseases and many of these plants were found to possess various phytochemicals, produced as secondary metabolites that could offer potential antimicrobial activity against various pathogens.

An attempt has been made in the present investigation to study the antibacterial activity of twelve pteridophytes collected from different places of Southern Assam.
Among the twelve pteridophytes, six pteridophytes namely Adiantum caudatum, Christella parasitica, Microlepia speluncae, Microsorum pteropus, Pteris multifida, $P$. vittata have shown inhibition zones against some of the potentially pathogenic Gram-positive and Gram-negative organisms tested.

A. caudatum is an ethnomedicinally imperative fern mostly used in the treatment of cough, fever ${ }^{[8,9]}$, burns, cuts and wounds ${ }^{[10]}$. This plant has also been reported to be used against pulmonary catarrach, bronchitis and asthma ${ }^{[11]}$. The qualitative phytochemical analysis of different solvent extract revealed the presence of phenols, saponins, steroids, tannins ${ }^{[12]}$. In the present study it was found that the acetone extract showed antimicrobial activity against two Gram-negative (E. coli, $12 \mathrm{~mm}$; P. vulgaris, $10 \mathrm{~mm}$ ). However, methanol extract was active against both Gram-positive and Gram-negative ( $S$. aureus, $14 \mathrm{~mm}$; P. vulgaris, $8 \mathrm{~mm}$ ). On the other hand, water and petroleum ether extract did not show any activity.

Various researchers ${ }^{[9,13,14]}$ have reported that the fern, C. parasitica has been used to treat gout and rheumatism by various ethnic people. Qualitative phytochemical analysis divulged the presence of phenols, tannins and coumarins ${ }^{[12]}$. Thus, when the plant was subjected to antibacterial screening, it was found that the methanol extract of fronds exhibited activity against $E$. coli (9 $\mathrm{mm}), S$. aureus $(7 \mathrm{~mm})$ and $P$. vulgaris $(8 \mathrm{~mm})$, whereas the petroleum ether and water extract was ineffective.

Decoction of the frond of M. speluncae has been used to treat toothache ${ }^{[15]}$. Consequently, when the plant was selected for antibacterial activity testing, it was found that the acetone extract was active against $S$. aureus $(8 \mathrm{~mm})$, whereas methanol extract was active against B. subtilis $(6 \mathrm{~mm})$ and $P$. aeruginosa $(8 \mathrm{~mm})$.

The frond extract of $M$. pteropus was reported to be used for treating cuts and wounds ${ }^{[13]}$. So when the antibacterial activity of the frond extracts was tested, the acetone extract showed activity against all tested organisms, while methanol extract did not inhibit $P$. vulgaris and water extract failed to inhibit $P$. vulgaris and S. aureus.

P. multifida possessed various activities that include heat-clearing, diuresis-promoting, antidiarrhoel, lucorrhoea-arresting, stranguria-treating and jaundice removing effects ${ }^{[16]}$. Various phytochemicals reported were flavonoids, sterols, amino acids, lactones or esters 
and phenolic components ${ }^{[17]}$. The acetone $(S$. aureus, $6 \mathrm{~mm}$; P. vulgaris, $7 \mathrm{~mm}$ ) and methanol extract (E. coli, $10 \mathrm{~mm}$; $P$. aeruginosa, $7 \mathrm{~mm}$ ) showed antimicrobial activity.

P. vittata is used by the ethnic people for treating dysentery and diarrhea ${ }^{[10]}$. Both the diseases were mostly caused by bacteria. Thus, in the present study an attempt has been made to study the antibacterial activity of this fern. Result revealed that the acetone, methanol and water extracts possessed antibacterial activity. Acetone extract was active against $P$. vulgaris, $9 \mathrm{~mm}$, whereas methanol extract against B. subtilis
(10 mm), E. coli $(7 \mathrm{~mm})$, S. aureus $(6 \mathrm{~mm})$ and water extract against $B$. subtilis $(7 \mathrm{~mm}), P$. aeruginosa (8 $\mathrm{mm})$.

Of the 12 ferns tested for antibacterial activity, 6 ferns were found to possess antibacterial activity against one or more organisms tested while the remaining 6 ferns did not show activity against any of the test organisms. The ferns that showed antibacterial activity were $C$. parasitica, $M$. speluncae, $P$. multifida, M. pteropus, A. caudatum, P. vittata. However, Thelypteris appendiculata, Tectaria decurrens, Pronephrum lakhimpurense, Calotropis procera,

TABLE 1: THE ANTIMICROBIAL ACTIVITIES OF CRUDE EXTRACTS OF THE SIX FERNS

\begin{tabular}{|c|c|c|c|c|}
\hline \multicolumn{5}{|c|}{ Christella parasitica } \\
\hline \multirow{2}{*}{ Name of the test organism } & \multicolumn{4}{|c|}{ Zones of inhibition in $\mathrm{mm}$ (excluding the disc diameter of $5 \mathrm{~mm}$ ) } \\
\hline & Aqueous & Methanol & Acetone & Petroleum ether \\
\hline Bacillus subtilis (MTCC 736) & - & - & - & - \\
\hline Escherichia coli (MTCC 1610) & - & $9.33 \pm 0.57$ & - & - \\
\hline Pseudomonas aeruginosa (MTCC 3541) & - & $7 \pm 1$ & - & - \\
\hline Staphylococcus aureus (MTCC 3160) & - & - & - & - \\
\hline Proteus vulgaris (MTCC 1771) & - & $8.33 \pm 1.52$ & - & - \\
\hline \multicolumn{5}{|c|}{ M. speluncae } \\
\hline Bacillus subtilis (MTCC 736) & - & $6.5 \pm 0.50$ & - & - \\
\hline Escherichia coli (MTCC 1610) & - & - & - & - \\
\hline Pseudomonas aeruginosa (MTCC 3541) & - & $8.33 \pm 0.57$ & - & - \\
\hline Staphylococcus aureus (MTCC 3160) & - & - & $7.66 \pm 0.57$ & - \\
\hline Proteus vulgaris (MTCC 1771) & - & - & - & - \\
\hline \multicolumn{5}{|c|}{ Pteris multifida } \\
\hline Bacillus subtilis (MTCC 736) & - & - & - & - \\
\hline Escherichia coli (MTCC 1610) & - & $11 \pm 1$ & - & - \\
\hline Pseudomonas aeruginosa (MTCC 3541) & - & $7 \pm 1$ & - & - \\
\hline Staphylococcus aureus (MTCC 3160) & - & - & $6.83 \pm 0.76$ & - \\
\hline Proteus vulgaris (MTCC 1771) & - & - & $7.83 \pm 1.04$ & - \\
\hline \multicolumn{5}{|c|}{ Microsorum pteropus } \\
\hline Bacillus subtilis (MTCC 736) & $8.66 \pm 1.52$ & $13.66 \pm 1.52$ & $9.33 \pm 1.15$ & - \\
\hline Escherichia coli (MTCC 1610) & $14.66 \pm 1.52$ & $14.33 \pm 0.57$ & $16.66 \pm 0.57$ & - \\
\hline Pseudomonas aeruginosa (MTCC 3541) & $13 \pm 1.89$ & $15.16 \pm 0.28$ & $14 \pm 1.73$ & - \\
\hline Staphylococcus aureus (MTCC 3160) & - & $7.7 \pm 0.68$ & $7.33 \pm 0.57$ & - \\
\hline Proteus vulgaris (MTCC 1771) & - & - & $9.33 \pm 1.15$ & - \\
\hline \multicolumn{5}{|c|}{ Adiantum caudatum } \\
\hline Bacillus subtilis (MTCC 736) & - & - & - & - \\
\hline Escherichia coli (MTCC 1610) & - & - & $14.16 \pm 1.89$ & - \\
\hline Pseudomonas aeruginosa (MTCC 3541) & - & - & - & - \\
\hline Staphylococcus aureus (MTCC 3160) & - & $14.66 \pm 0.57$ & - & - \\
\hline Proteus vulgaris (MTCC 1771) & - & $9.33 \pm 1.15$ & $11.33 \pm 1.52$ & - \\
\hline \multicolumn{5}{|c|}{ Pteris vittata } \\
\hline Bacillus subtilis (MTCC 736) & $8.33 \pm 1.15$ & $11.66 \pm 1.52$ & - & - \\
\hline Escherichia coli (MTCC 1610) & - & $7 \pm 2$ & - & - \\
\hline Pseudomonas aeruginosa (MTCC 3541) & $7.66 \pm 2.51$ & - & - & - \\
\hline Staphylococcus aureus (MTCC 3160) & - & $7.33 \pm .942$ & - & - \\
\hline Proteus vulgaris (MTCC 1771) & - & - & $10.66 \pm 1.52$ & - \\
\hline
\end{tabular}

'-' No inhibition zone was observed 
Castanea dentata, $P$. cretica have not shown any inhibition zone against any of the tested microorganisms (Table 1).

\section{Acknowledgements:}

Authors acknowledge financial assistance received from UGC sponsored MRP (F.No.41-420/2012(SR)) and also infrastructural facilities received under DBT sponsored Institutional Biotech Hub Project of Karimganj College (BCIL/NER-BPMC/2010, November 30, 2010). The first author acknowledges help and support received from Dr. Amitabha Bhattacharjee, Department of Microbiology, Assistant Professor, Assam University, Silchar.

\section{Financial support and sponsorship:}

Nil.

\section{REFERENCES}

1. Chanda S, Vyas BRM, Vaghasiya Y, Patel H. Global resistance trends and the potential impact of methicillin resistant Staphylococcus aureus (MRSA) and its solutions. In: MendezVilas A, editor. Current Research, Technology and Education Topics in Applied Microbiology and Microbial Biotechnology. Badajoz, Spain: Formatex Research Center; 2010. p. 529-36.

2. Odugbemi T. Outlines and Pictures of Medicinal Plants from Nigeria. $1^{\text {st }}$ ed. Nigeria: University of Lagos Press; 2006.

3. Khan A, Haque E, Rahman MM, Mosaddik A, Rahman M, Sultana N. Isolation of antibacterial constituent from rhizome of Drynaria quercifolia and its sub-acute toxicological studies. DARU J Pharm Sci 2007;15:205-11.

4. Fagbemi JF, Ugoji E, Adenipekun T, Adelowotan O. Evaluation of the antimicrobial properties of unripe banana (Musa sapientum L.), lemon grass (Cymbopogon citratus S.) and turmeric (Curcuma longa L.) on pathogens. Afr J Biotechnol 2009;8:1176-82.
5. Banerjee RD, Sen SP. Antibiotic activity of pteridophytes. Econ Bot 1980;34:284-98.

6. Basile A, Spagnuolo V, Giordano S, Sorrentino C, Lavitola A, Castaldo RC. Induction of antibacterial activity by $\alpha$-Doligogalacturonides in Nephrolepis sp. (pteridophyta). Int J Antimicrob Agents 1997;8:131-34.

7. Grierson DS, Afolayan AJ. Antibacterial activity of some indigenous plants used for the treatment of wounds in the Eastern Cape, South Africa. J Ethnopharmacol 1999;66:103-06.

8. Sen A, Ghosh PD. A Note on the ethno botanical studies of some pteridophytes in Assam, India. J Tradit Know 2011;10:292-95.

9. http://www.vedamsbooks.in/no107634/cart.php.

10. Thulsi Rao K, Reddy RN, Pattanaik C, Reddy CS. Ethnomedicinal importance of Pteridophytes used by Chenchus of Nallamalais, Andhra Pradesh, India. Ethnobot Leaflets 2007;11:6-10.

11. Kaushik P, Dhiman AK. Common medicinal pteridophytes. Indian Fern J 1995;12:139-45.

12. Mithraja MJ, Antonisamy JM, Mahesh M, Paul ZM, Jeeva S. Inter-specific variation studies on the phyto-constituents of Christella and Adiantum using phytochemical methods. Asian Pac J Trop Biomed 2012;S40-S5.

13. Dutta Choudhury M, Das B, Mazumder PB. Fern Flora and Fern Allies of Southern Assam-Ethno-medico botanical studies and certain conservation aspects. Udaipur, India: Scichem Publishing House; 2009.

14. Rawat MS, Chowdhury S. Ethno Medico Botany of Arunachal Pradesh (Nishi and Apatani Tribe). Dehradun: Bishan Singh Mahendra Pal Singh; 1998.

15. Zepernick B. Arzneipflanzen der polyneser. Berlin: Dietrich Reimer Verlag GmbH; 1972.

16. Chinese Materica Medica, Editorial Board of State Administration of Traditional Chinese Medicine. Vol-2. Shanghai: Shanghai Scientific and Technical Publishers; 1999. p.122-23.

17. Yu C, Chen J, Huang L. A study on the antitumour effect of flavonoids from Pteris multifida Poir. In H22 tumour-brearing mice. Afr J Tradit Complement Altern Med 2013;10:459-63. 